\title{
CLASSIFICAÇÃO DAS FORMAS DE PRAIAS NO LITORAL SUL FLUMINENSE
}

\author{
Karlany Brandão ${ }^{(a)}$, Eduardo Manuel Rosa Bulhões ${ }^{(b)}$ \\ (a) Departamento de Geografia de Campos, Universidade Federal Fluminense, karlanybrandao@id.uff.br \\ (b)Departamento de Geografia de Campos, Universidade Federal Fluminense, eduardobulhoes@id.uff.br
}

\section{Eixo: DINÂMICA E GESTÃO DE ZONAS COSTEIRAS}

\begin{abstract}
Resumo
Praias de enseada são definidas como ambientes arenosos bordeados por margens rochosas ou mesmo artificiais, que assumem uma curvatura definida em função da disponibilidade de sedimentos e do padrão de circulação hidrodinâmica, sobretudo aquele induzido por ondas oceânicas. O objetivo desse trabalho é mapear na escala de detalhes as praias do litoral sul fluminense. O método para alcançar tal objetivo consistiu na utilização das imagens de satélite do Google Earth para reconhecimento da área de estudo, além de Ortofotos do Projeto RJ25 do IBGE para que ocorra o detalhamento das características das praias e a coleta de dados aos quais auxiliam na classificação das mesmas, podendo ser praias de enseada ou praias retilíneas, organizando-os em um sistema de informações geográficas, onde consequentemente obteve- se resultados iniciais, no qual o município de Paraty se destaca comportando 48,46\% das praias de enseada presentes na região do Litoral Sul Fluminense.
\end{abstract}

Palavras chave: Praias de Baixa Energia, Mapeamento Costeiro, Litoral das Escarpas Cristalinas.

\section{Introdução}

O Litoral Sul Fluminense é formado pela Baía de Ilha Grande e a Baía de Sepetiba, abrangendo os municípios de Paraty, Angra dos Reis, Itaguaí e Mangaratiba. Considerando a compartimentação do litoral proposta por Muehe (1998) o litoral em questão compõe o Macrocompartimento Litoral das Escarpas Cristalinas Norte, que se extende entre a baía de Ilha Grande / RJ, até São Vicente/ SP. O autor indica as principais carcaterísticas deste litoral e destaca a presença de inúmeras ilhas, pequenas enseadas e planícies costeiras de baixa expressão, compondo um litoral de aspecto afogado.

Considerando ainda como feições características deste litoral a ocorrência de estuários, ilhotas e lajes submersas, depósitos lamosos dentre outras o foco deste trabalho é a ocorrência de centenas de praias de enseada. De acordo com Bulhões e Fernandez(2016) praias de enseada são definidas como ambientes arenosos bordeados por margens rochosas ou artificiais, cuja curvatura em planta é definida em função da disponibilidade de sedimentos e do padrão de circulação hidrodinâmica.

Jackson et al. (2005) apontam que todas as praias estão apoiadas sobre estrutura geológica pretérita e é essa estrutura que determina os limites pelos quais a praia se forma e se espacializa. Os processos 
hidrodinâmicos locais também são controlados pela disposição desta estrutura geológica pretérita, como a presença de costões rochosos, ilhas, lajes submersas e etc. Mahiques et al. (1998) indicam que a interação entre a direção de incidência das ondas com a extensão e orientação das aberturas das enseadas e ainda, a presença de obstáculos naturais ou artificiais na plataforma continental interna, levam a ocorrência de variações na dinâmica das baías, e é por isso que estas são chamadas de praias protegidas ou praias embaiadas. As diferenças nos níveis de energia entre as enseadas estão então fortemente associadas à direção de incidência das ondas e à orientação das aberturas de enseadas.

O objetivo desse trabalho é mapear na escala de detalhe as praias do Litoral Sul Fluminense, extrair suas principais características em planta e classifica- las em praias de enseada ou praias retilíneas, dando uma ênfase para a primeira. Destaca-se, conforme Bowman et al (2009) que o estudo das características geométricas em planta é o primeiro passo para o aprofundamento da pesquisa sobre praias de enseada e esta é a proposta deste trabalho.

\section{2. Área de Estudo}

A baía de Ilha Grande e de Sepetiba se localizam na região do Litoral Sul Fluminense (Figura 01), área com forte apelo turístico, conhecido como Costa Verde. Este compartimento costeiro é marcado pela ocorrência de dezenas de praias de enseada com distintos comprimentos, larguras e orientações. São consideradas também como praias de baixa energia, protegidas frente às ondulações entre reentrâncias de promontórios rochosos ou obras costeiras. Davies (1972) define praias de baixa energia como ambientes localizados em mares interiores e/ou protegidos de marulhos e aonde a ação das ondas é mínima comparando com os ambientes expostos ao oceano aberto.

Ao descrever a região da baía de Ilha Grande, Mahiques (1987) destaca a grande quantidade de praias arenosas, podendo ser de enseada ou retilínea, presentes na área e a formação de uma linha de costa composta por pontões cristalinos dentro da região costeira. A baía ainda apresenta parte da Serra do Mar, caracterizada como "uma escarpa erosiva, com altitudes variaveis entre 800 a 1.200m. Essas escarpas, cuja origem está ligada à atividade tectonica de blocos de falha, chegam a atingir a linha da costa sem que se verifique a presença de formas intermediárias do relevo.” (Mahiques, 1987).

DOI - 10.20396/sbgfa.v1i2017.8122 - ISBN 978-85-85369-16-3 


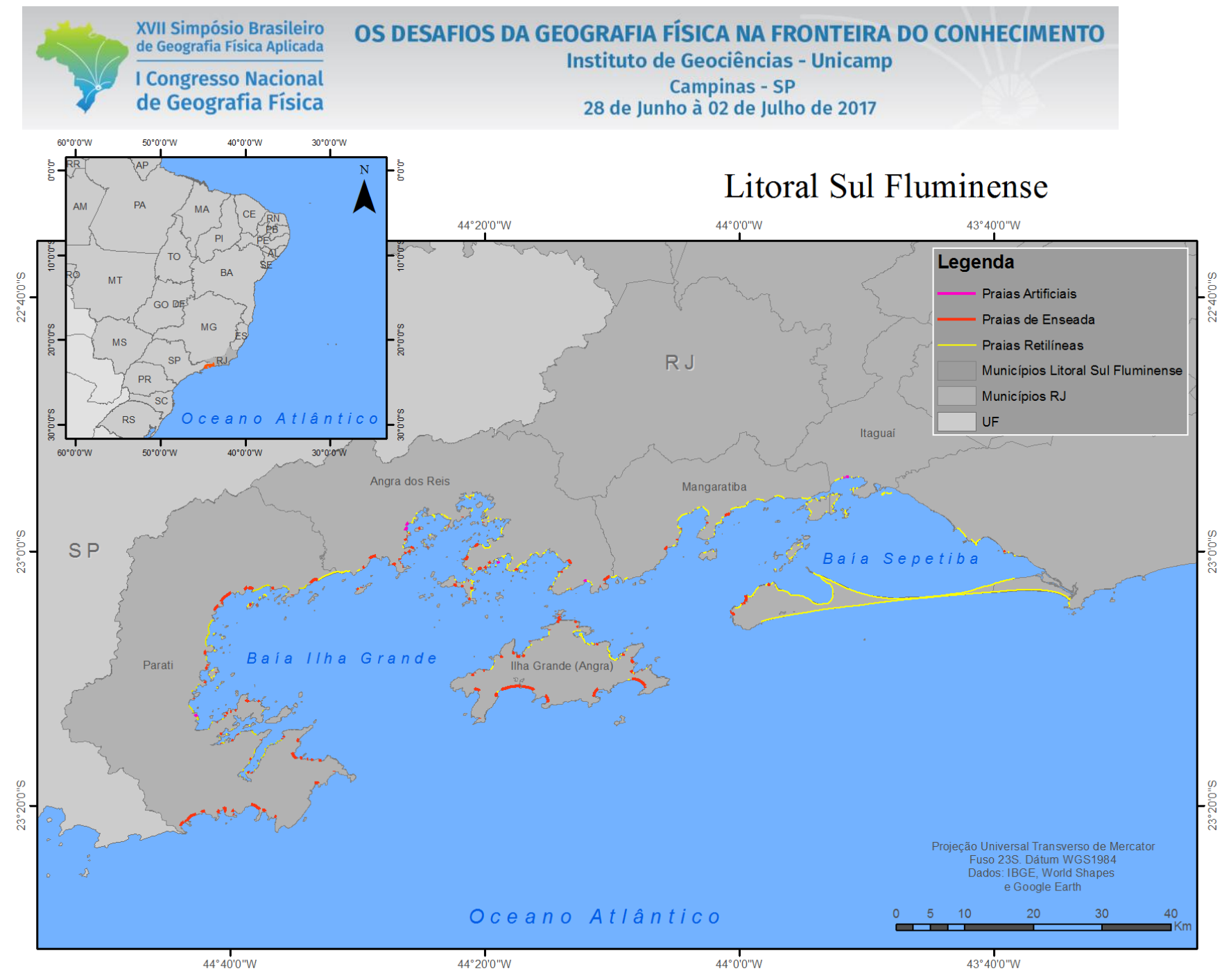

Figura 01: Mapa de Localização da Área de Estudo e Classificação das Formas de Praias.

\section{Materiais e Métodos}

O recorte espacial já apresentado foi analisado utilizando inicialmente as imagens de satélite disponíveis no programa Google Earth Pro, com o intuito de reconhecer o Litoral Sul Fluminense e identificar suas principais feições costeiras. Adicionalmente foram utilizadas Ortofotos do Projeto RJ25 do IBGE para detalhar as características das formas de praias, consequentemente obter a classificação das mesmas, segundo as características apresentadas e analisadas, e assim computar as informações em um sitema de informação geográfica. O processamento dos dados vetoriais gerados foi feito com suporte dos programas QGis e ArcMap, assim como a geração dos resultados iniciais.

\section{Resultados Iniciais}

Como primeiro resultado tem- se a produção do mapa com demarcação de todas as praias arenosas, as quais são classificadas em três categorias: Praias Retilíneas; Praias de Enseada; Praias Artificiais. Dessa 
forma quando as praias são encontradas entre dois promontórios rochosos são consideradas de formação natural, porém quando encontradas entre obras costeiras, como um abrigo portuário, são consideradas praias de formação artificial. As mesmas se localizam dentro das baías de Ilha Grande e Sepetiba e podem ser identificadas (Figura 01) através da marcação de cores amarela, vermelho e rosa, respectivamente. Tendo por finalidade identificar a área proposta para o estudo e posteriormente auxiliar de uma melhor forma a análise necessária para obtenção de dados e produção de resultados para alcançar os objetivos já propostos.

Foi, então, identificado um total de 608 praias arenosas, com distintas características entre elas, de forma que ocorre a presença de praias de enseada, com formação natural ou artificial, e praias retilíneas. Na tabela I são apresentados dados referentes ao número total de praias arenosas identificadas na região, subdivididas através dos municípios de Paraty, Angra dos Reis, Mangaratiba, Sepetiba e as diversas ilhas que se localizam no compartimento costeiro aqui estudado, como também a identificação do número total de praias de enseada subdivididas pela sua formação natural ou não. Essa subdivisão das praias entre os municípios e as diversas ilhas foi feita com o intuito de melhor organização dos dados então encontrados e expostos na Tabela I.

Tabela I: Classifiação das Formas de Praias do Sul Fluminense

\begin{tabular}{|c|c|c|c|c|c|c|c|}
\hline \multirow{2}{*}{$\begin{array}{l}\text { Local } \\
\text { Paraty }\end{array}$} & \multirow{2}{*}{$\begin{array}{c}\begin{array}{c}\text { Número } \\
\text { Total de } \\
\text { Praias } \\
(\boldsymbol{n})\end{array} \\
130\end{array}$} & \multicolumn{2}{|c|}{$\begin{array}{c}\text { Praias Retilíneas } \\
n \text { e } \%\end{array}$} & \multicolumn{2}{|c|}{$\begin{array}{c}\text { Praias de Enseada } \\
\qquad n \mathrm{e} \%\end{array}$} & \multicolumn{2}{|c|}{$\begin{array}{c}\text { Praias de Enseada } \\
\text { Artificiais } \\
n \mathbf{e} \%\end{array}$} \\
\hline & & 67 & 51,54 & 63 & 48,46 & 1 & 0,77 \\
\hline Angra dos Reis & 168 & 126 & 75,00 & 42 & 25,00 & 4 & 2,38 \\
\hline Mangaratiba & 40 & 33 & 82,50 & 7 & 17,50 & 0 & 0,00 \\
\hline Sepetiba & 69 & 62 & 89,86 & 7 & 10,14 & 16 & 23,19 \\
\hline Ilhas & 201 & 147 & 73,13 & 54 & 26,87 & 0 & 0,00 \\
\hline Total & 608 & 435 & 71,55 & 173 & 28,45 & 21 & 3,45 \\
\hline
\end{tabular}

Através dos dados apresentados na Tabela I pode-se, então, comparar o número total de praias classificadas entre retilíneas e de enseadas, sendo a primeira apresentando 435 unidades, ou seja, 71,55\% do total de praias, e a última num total de 194 unidades, ou seja, 31,9\%. Porém dentre estas, 21 unidades são de formação artificial (representando um valor de 3,45\% do total de praias), ou seja, não se localizam 
entre promontórios rochosos, mas entre obras costeiras, as quais são suficientes para mudar a orientação e hidrodinâmica da praia em questão. A Baía de Sepetiba comporta o maior número de praias de enseada artificiais do Litoral Sul Fluminense (16 unidades), devido à construção da Orla da praia Coroa Grande, no município de Itaguaí, onde se tem obras costeiras que formam pequenas enseadas artificiais, dessa forma possuindo um número maior de praias de enseada artificial se comparado as praias de enseada de formação natural.

Ao considerar as praias de enseada por formação natural, o maior número é comportado pelo município de Paraty, que de um total de 130 unidades, 63 são praias de enseada, ou seja, 48,4\%, e apenas uma unidade sendo praia de enseada artificial, totalizando assim 64 praias de enseada e 67 praias retilíneas, a vista disso é possivel compreender a forte presença de praias de enseada contidas na região do Macrocompartimento das Escarpas Cristalinas Norte.

\section{Considerações Finais}

Através dos resultados iniciais aqui indicados, pode- se considerar que o Litoral Sul Fluminense é um litoral recortado, onde se tem uma ocorrência de grande presença de praias arenosas, destacando aqui as classificadas como praias de enseada, onde é evidenciado o municipio de Paraty como o maior comportador dessas praias, e contrapondo ao município de Mangaratiba que é o menor comportador das mesmas, sendo identificadas apenas 7 praias de enseada dentre as 40 praias do total, e assim apresentando apenas 17,5 \% como praias de enseada. Já as ilhas apresentam apenas praias de enseada por formação natural, sendo assim, por mais que a maioria receba a ação do homem, não ocorreu nenhuma obra costeira nas mesmas a ponto de interferir em sua hidrodinâmica. Já as praias classificadas como retilíneas são representadas com um total de 435 unidades de um total de 608 praias, ou seja, 71,55\%. As diversas ilhas que compõem esse litoral são as responsáveis por comportar a maior parte dessas praias retilíneas.

Para futuros desenvolvimentos desta pesquisa tem-se como intuito a caracterização mais detalhada das praias de enseada já identificadas, como por exemplo, classificar de acordo com a orientação e a exposição relativa destas enseadas frente à ondas de alta energia.

\section{REFERÊNCIAS}

BOWMAN,D; GUILLÉN,J; PELLEGRINO,V. Plan view Geometry and morphological characteristics of pocket beaches on the Catalan coast. Geomorphology 108, 2009, pp. 191- 199.

BULHOES, E.; FERNANDEZ, G. B. Aspectos Morfodinâmicos em Praias de Enseada: Estudo de Caso em Armação dos Búzios, RJ. Revista Brasileira de Geomorfologia. v. 17, n. 2, p. 253-271, 2016.

DAVIES, J.L. 1972. Geographical Variation in Coastal Development. Oliver \&Boyd. Edinburgh.

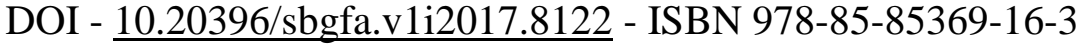


JACKSON, D.W.T., COOPER, J.A.G. and DEL RIO, L., 2005. Geological Control of Beach Morphodynamic State. Marine Geology.216, pp. 297-314.

MAHIQUES, M.M. (1987). Considerações sobre os sedimentos e superfície de fundo da Baía da Ilha Grande, Estado do Rio e Janeiro. Dissertação de Mestrado. Instituto Oceanográfico, USP. São Paulo, 2 Vol.

MAHIQUES, M.M.; TESSLER, M.G. e FURTADO, V.V. (1998) Characterizationof Energy Gradient in Enclosed Baysof Ubatuba Region, South-Eastern Brazil. Estuarine, Coastal and Shelf Science. Vol. 47. pp. 431-446.

MUEHE, D. (1998b) O Litoral Brasileiro e sua Compartimentação. In: Guerra, A. J. T. \& Cunha, S.B. (org).Geomorfologia do Brasil. Cap. 7. Ed. Bertrand Brasil. pp. 273-349. 